\title{
Polyamine Catabolism
}

National Cancer Institute

\section{Source}

National Cancer Institute. Polyamine Catabolism. NCI Thesaurus. Code C19824.

Polyamine Catabolism is a destructive metabolic process in which low molecular weight cations, containing two or more amine groups (polyamines), are converted into excreted compounds. 